\title{
Clinical Study \\ Randomized Clinical Trial of Composite Restorations in Primary Teeth: Effect of Adhesive System after Three Years
}

\author{
Secil Bektaş Donmez, ${ }^{1}$ Melek D. Turgut, ${ }^{1}$ Serdar Uysal, ${ }^{2}$ Pinar Ozdemir, ${ }^{3}$ \\ Meryem Tekcicek, ${ }^{1}$ Brigitte Zimmerli, ${ }^{4}$ and Adrian Lussi ${ }^{4}$ \\ ${ }^{1}$ Department of Pediatric Dentistry, Hacettepe University, Ankara, Turkey \\ ${ }^{2}$ Department of Maxillofacial Radiology, Hacettepe University, Ankara, Turkey \\ ${ }^{3}$ Department of Biostatistics, Hacettepe University, Ankara, Turkey \\ ${ }^{4}$ Department of Preventive, Restorative and Pediatric Dentistry, University of Bern, Bern, Switzerland
}

Correspondence should be addressed to Melek D. Turgut; melekturgut@yahoo.com

Received 17 August 2016; Accepted 15 September 2016

Academic Editor: Tamer Tüzüner

Copyright (C) 2016 Secil Bektaş Donmez et al. This is an open access article distributed under the Creative Commons Attribution License, which permits unrestricted use, distribution, and reproduction in any medium, provided the original work is properly cited.

\begin{abstract}
The purpose of this study was to assess the clinical performance of composite restorations placed with different adhesive systems in primary teeth. In 32 patients, 128 composite restorations were placed using a split-mouth design as follows (4 groups/patient): three-step etch-and-rinse (Group 1), two-step etch-and-rinse (Group 2), two-step self-etch (Group 3), and one-step self-etch (Group 4). The restorations were clinically evaluated at baseline and at 6,18 , and 36 months according to the FDI criteria. There was no significant difference between the adhesive systems in retention of the restorations $(p>0.05)$. Over time, there was a statistically significant decrease in marginal adaptation in all groups, whereas surface and marginal staining significantly increased in Groups 3 and $4(p<0.05)$. The etch-and-rinse adhesive systems resulted in better marginal adaptation than the self-etch adhesive systems $(p<0.05)$. It was concluded that preetching of the primary enamel might help improve the clinical performance of the self-etch adhesive systems in primary teeth.
\end{abstract}

\section{Introduction}

Tooth-colored materials are widely used in pediatric dentistry for the restoration of carious primary teeth [1]. Of these materials, resin composites have been gaining increasing popularity over the past few decades because of their favorable esthetic and mechanical properties [2,3].

Composite restorations are placed following pretreatment of the cavities with an adhesive system. Until recently, etch-and-rinse adhesive systems have been regarded as the gold standard owing to their good clinical and laboratory record [4]. However, these adhesive systems involve numerous application steps. In pediatric dentistry, and especially when treating uncooperative children, such a timeconsuming technique is undesirable and oftentimes difficult to carry through [5]. To simplify the bonding procedure and to reduce technique sensitivity of the etch-and-rinse adhesive systems, self-etch adhesive systems have been developed
[6]. For the treatment of primary teeth, the etch-and-rinse adhesive systems may offer the advantage of a separate acid etching step, which has been suggested to be necessary for the prismless enamel [7]. Compared to the permanent dentin, the inorganic content of intratubular primary dentin is less. The number of dentinal tubules is lower, resulting in less surface moisture and increased susceptibility of the primary dentin to decalcification $[5,8,9]$. In this regard, the self-etch adhesive systems may offer the advantage of limited decalcification of the primary dentin [10]. The number of clinical studies comparing etch-and-rinse adhesive systems with self-etch adhesive systems, however, is limited which means that the superiority of any one category of adhesive system in primary teeth has yet to be firmly established [11-13]. To the best of our knowledge, no study has yet compared the clinical efficacy of various types of etch-and-rinse or self-etch adhesive systems in primary teeth. Therefore, the aim of this clinical trial was to evaluate the clinical performance of composite restorations 


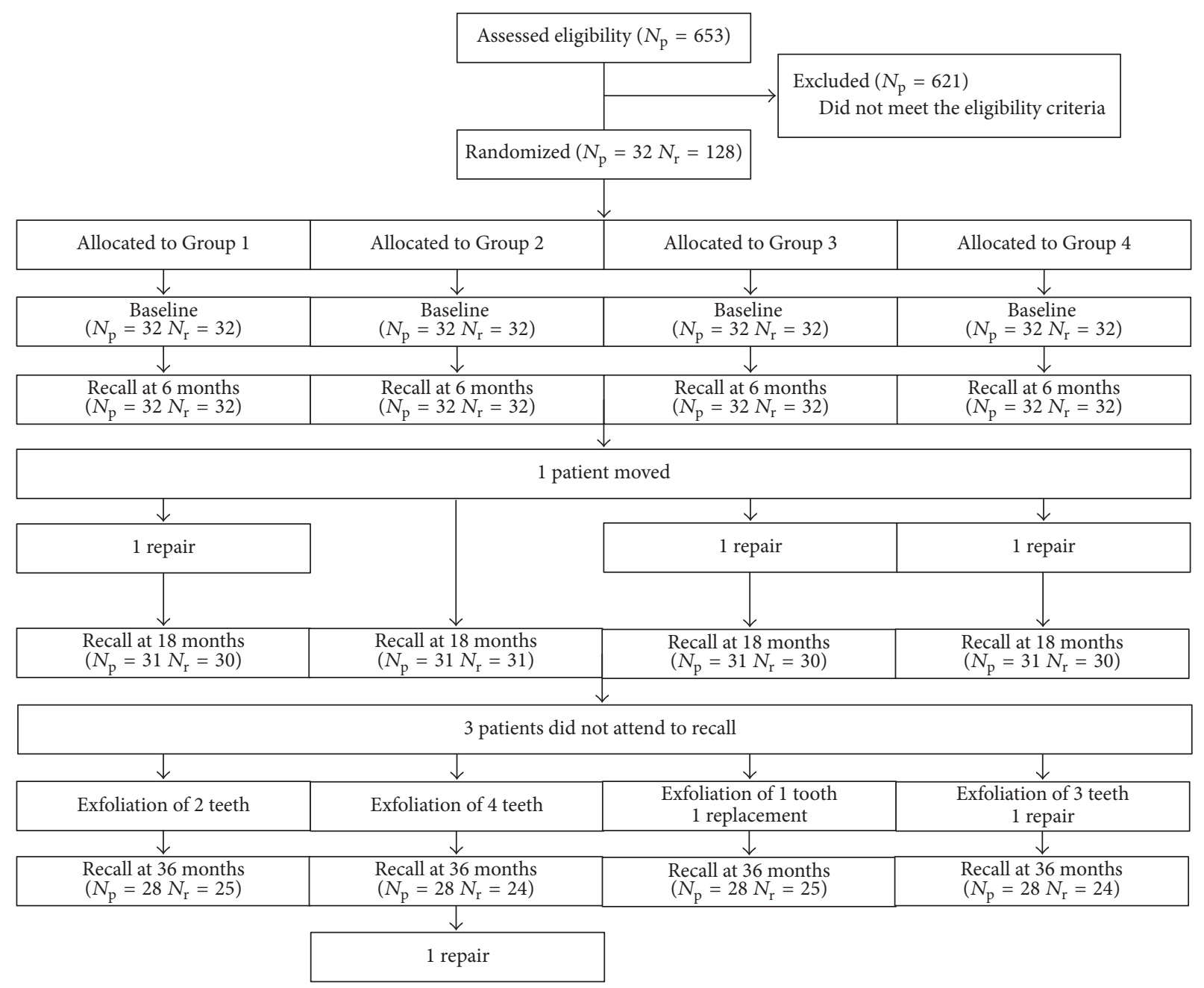

FIgURE 1: Flow diagram. $N_{\mathrm{p}}$ : number of patients, $N_{\mathrm{r}}$ : number of restorations.

placed with one of four adhesive systems (a three-step etchand-rinse, a two-step etch-and-rinse, a two-step self-etch, or a one-step self-etch adhesive system) in primary teeth. The null hypothesis to be tested was that there was no difference in the clinical performance of the adhesive systems after 3 years.

\section{Methods}

The study was approved by the local ethics committee of the university (Project number FON 08/58). A total of 653 healthy children aged 4-7 years attending the Pediatric Dentistry Department were examined to determine their eligibility for the study. Thirty-two of the children were selected as they met the study criteria including the presence of four first and/or second primary molars with proximal caries extending into dentin and having occlusal and proximal contacts (Figure 1). The procedure, risks, possible discomforts, and benefits were explained to the parents and their informed consents were obtained prior to the study.

The four carious primary molars in each patient were randomly allocated into four groups. For randomization (beginning from the lower right quadrant followed by the lower left quadrant, upper left quadrant, and upper right quadrant), the four teeth in each patient were sorted. From the web site (https://www.random.org/), sequences for group numbers ( 1 to 4 ) were generated. The group numbers in each sequence and the teeth were matched.

The restorations were placed by one trained operator. Local anesthesia was administered, a rubber dam was placed, and nonbeveled Class II cavities were prepared on the primary teeth.

\section{Restoration Groups}

In Group 1, a three-step etch-and-rinse adhesive system (OptiBond FL, Kerr Corporation, Orange, CA, USA) was used. The cavity was etched with $37,5 \%$ phosphoric acid (30 s for enamel and $15 \mathrm{~s}$ for dentin), rinsed thoroughly for $15 \mathrm{~s}$, and gently air-dried for $5 \mathrm{~s}$. The primer was applied by light scrubbing motions for $15 \mathrm{~s}$ and then gently air-dried for $5 \mathrm{~s}$. The adhesive was applied in a uniform layer and light-cured for $30 \mathrm{~s}$. 


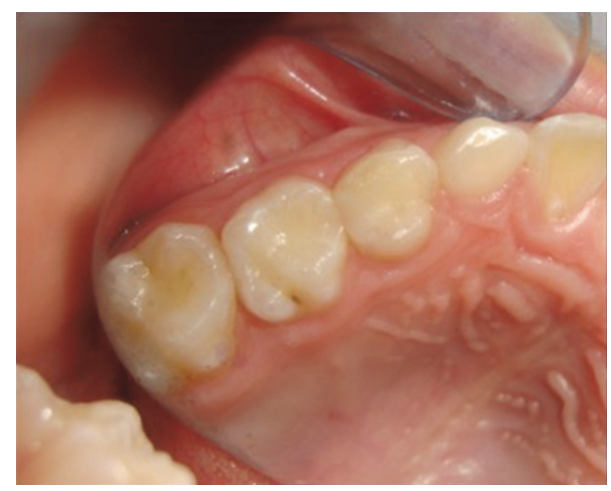

(a)

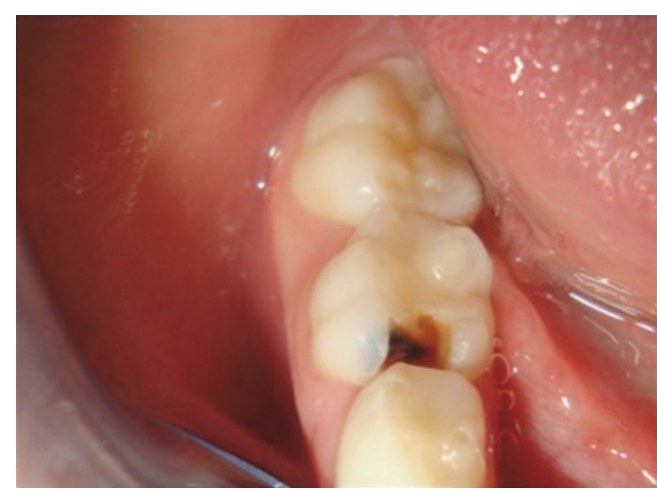

(b)

FIGURE 2: Clinically excellent occlusomesial restoration on upper second primary molar at 36 months (a); lost restoration on lower second primary molar (loss at 30 months) (b).

In Group 2, a two-step etch-and-rinse adhesive system (XP Bond, Dentsply DeTrey, Konstanz, Germany) was used. The cavity was etched with $36 \%$ phosphoric acid for the same durations as in Group 1. The adhesive was applied, left undisturbed for $20 \mathrm{~s}$, air-dried thoroughly for $5 \mathrm{~s}$ to evaporate the solvent, and light-cured for $20 \mathrm{~s}$.

In Group 3, a two-step self-etch adhesive system (AdheSE, Ivoclar Vivadent, Schaan, Liechtenstein) was used. The primer was applied for $15 \mathrm{~s}$ and brushed for another $15 \mathrm{~s}$, and excess primer was then dispersed with a strong air stream for $5 \mathrm{~s}$. The bond was applied, dispersed with a weak air stream for $5 \mathrm{~s}$, and light-cured for $10 \mathrm{~s}$.

In Group 4, a one-step self-etch adhesive system (G-Bond GC Corporation, Tokyo, Japan) was used. The adhesive was applied, left undisturbed for $10 \mathrm{~s}$, dried thoroughly under maximum air pressure for $5 \mathrm{~s}$, and light-cured for $10 \mathrm{~s}$.

Following treatment of the cavity with one of the four adhesive systems, a resin composite (Esthet-X, Dentsply DeTrey, Konstanz, Germany) was placed in $2 \mathrm{~mm}$ increments, each light-cured for $20 \mathrm{~s}$ with a visible light curing unit (Hilux Ultra Plus, Benlioglu Dental, Ankara, Turkey; light curing intensity of $700 \mathrm{~mW} / \mathrm{cm}^{2}$ ). Finishing and polishing of the restorations were done with diamond finishing burs, yellow rubber cups (Diatech, Diatech Dental AG, Heerbrugg, Switzerland), and aluminum oxide discs (Sof-Lex, 3M/ESPE, Seefeld, Germany).

\section{Clinical Assessment}

All restorations were clinically evaluated at baseline (1 week after placement) and after 6,18 , and 36 months by one trained operator who was blinded to the restorative group under examination. Standard photographs of the restorations were taken and the assessment was made according to the FDI World Dental Federation criteria with codes ranging from 1 to 5 (Code 1: clinically excellent, Code 2: clinically good, after polishing very good, Code 3 : clinically sufficient, Code 4: clinically unsatisfactory, repair is necessary, and Code 5: clinically poor, replacement is necessary) (Table 1) [14].
To determine the intraexaminer reliability, 20 restorations at different recalls were reevaluated with an interval of 1 week and statistically evaluated with Kappa test.

\section{Radiographical Assessment}

All restorations were radiographically evaluated at baseline and after 18 and 36 months by one trained operator who was blinded to the restorative group under examination. Radiographic examination was not performed at 6 months to lessen radiation exposure. The periapical radiographs were obtained with the parallel technique and scanned at $2400 \mathrm{dpi}$ with a scanner (Epson Expression 10000 XL, Seiko Epson Co., Nagano, Japan). From these images, the tooth-restoration interface was analyzed at $\times 600$ magnification using an image analysis program (ImageJ 1.43n, NIH, USA).

To determine the intraexaminer reliability, all radiographs were reevaluated after 1 week by the same operator. Intraexaminer reliability was analyzed by intraclass correlation coefficient (ICC).

\section{Statistical Analyses}

The statistical analyses were performed by a statistician. The data obtained were subjected to statistical analysis at a 0.05 level of significance. For each recall time, the groups were compared using the Kruskal-Wallis test (intergroup comparisons). The differences between recall times in each group were compared using the Friedman test (intragroup comparisons).

\section{Results}

Of the 32 children (mean age $5.96 \pm 0.82$ years) who participated in the study, 27 (84.4\%) were girls and 5 (15.6\%) were boys. The intraexaminer reliability of the clinical and radiological assessments was $96 \%$ and $82 \%$, respectively. Examples of a clinically excellent restoration and a lost restoration are shown in Figure 2. 


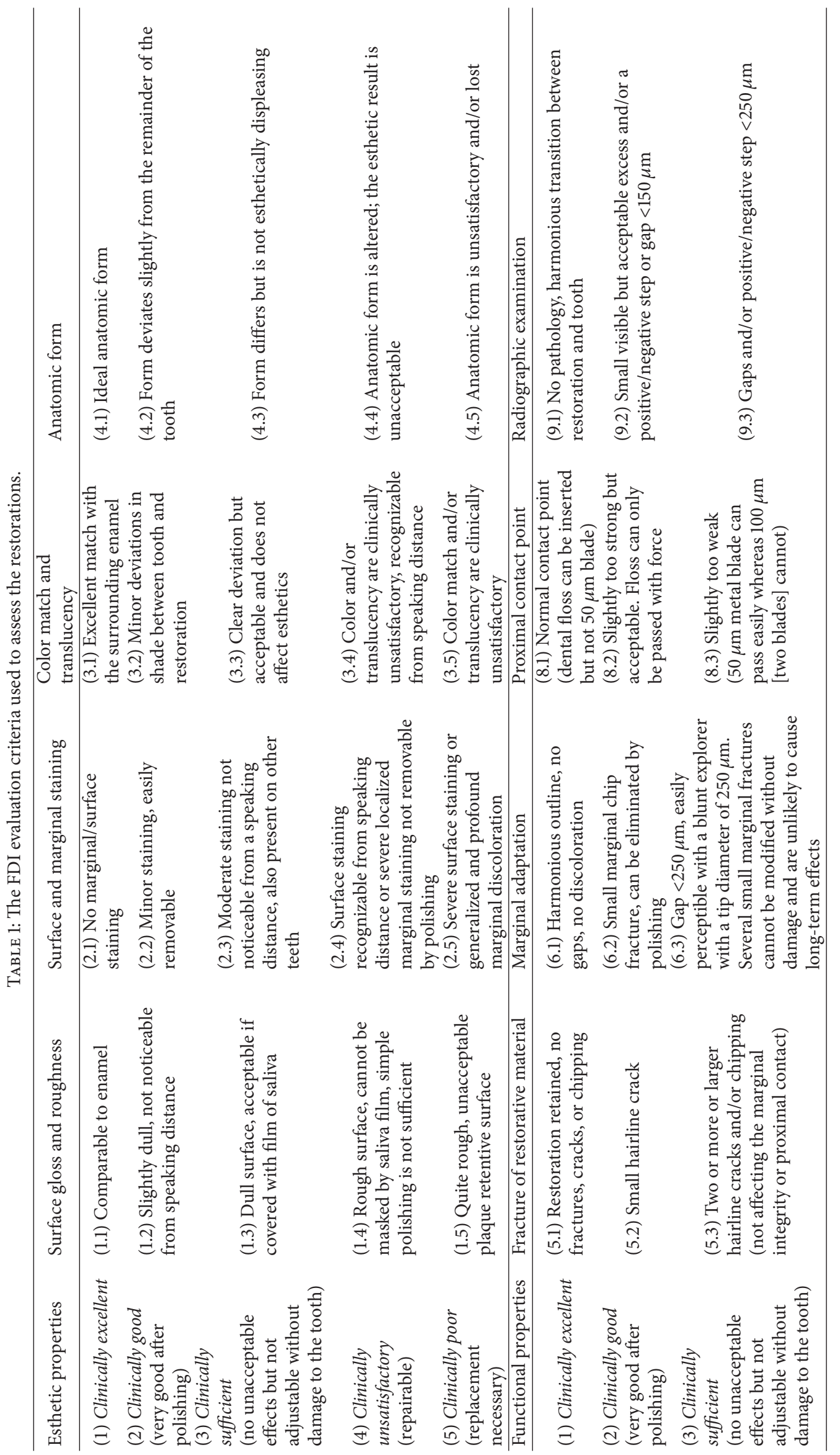




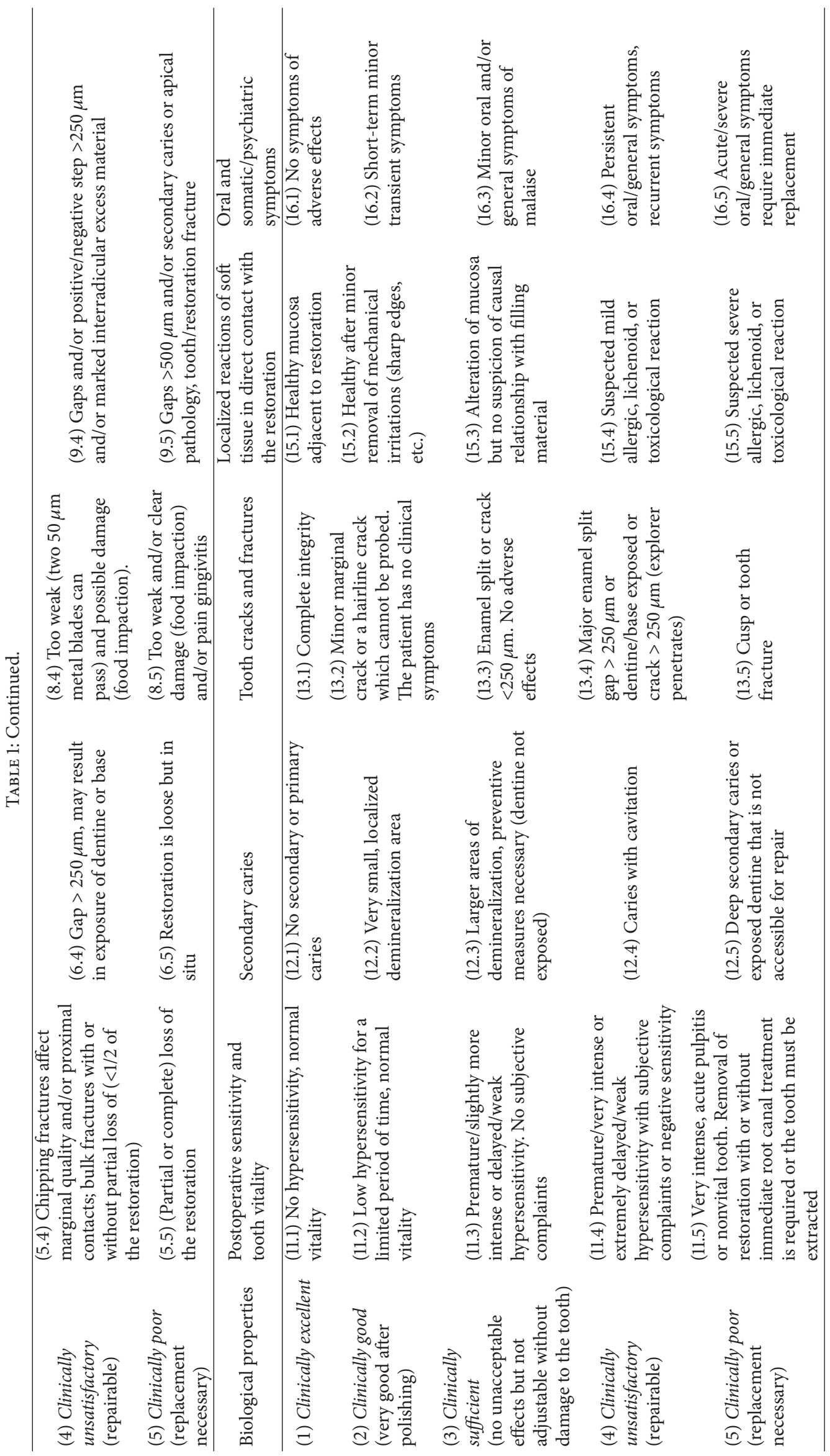


TABLE 2: Esthetic properties of the groups.

\begin{tabular}{|c|c|c|c|c|c|c|}
\hline Criteria & Time & Score & $\begin{array}{c}\text { Group } 1 \\
n(\%)\end{array}$ & $\begin{array}{c}\text { Group } 2 \\
n(\%)\end{array}$ & $\begin{array}{c}\text { Group } 3 \\
n(\%)\end{array}$ & $\begin{array}{c}\text { Group } 4 \\
n(\%)\end{array}$ \\
\hline \multirow{4}{*}{ Surface gloss and roughness } & Baseline & 1 & $32(100)$ & $32(100)$ & $32(100)$ & $32(100)$ \\
\hline & 6 months & 1 & $32(100)$ & $32(100)$ & $32(100)$ & $32(100)$ \\
\hline & 18 months & 1 & $30(100)$ & $31(100)$ & $30(100)$ & $30(100)$ \\
\hline & 36 months & 1 & $25(100)$ & $24(100)$ & $25(100)$ & $24(100)$ \\
\hline \multirow{10}{*}{ Surface and marginal staining ${ }^{*}$} & \multirow{2}{*}{ Baseline } & 1 & $32(100)$ & $32(100)$ & $32(100)$ & $30(93.8)$ \\
\hline & & 3 & & & & $2(6.3)$ \\
\hline & \multirow{2}{*}{6 months } & 1 & $32(100)$ & $31(96.9)$ & $31(96.9)$ & $30(93.8)$ \\
\hline & & 3 & & $1(3.1)$ & $1(3.1)$ & $2(6.3)$ \\
\hline & \multirow{3}{*}{18 months } & 1 & $29(96.7)$ & $29(93.5)$ & $27(90)$ & $26(86.7)$ \\
\hline & & 2 & & $1(3.2)$ & & \\
\hline & & 3 & $1(3.3)$ & $1(3.2)$ & $3(10)$ & $4(13.3)$ \\
\hline & \multirow{3}{*}{36 months } & 1 & $22(88)$ & $21(87.5)$ & $17(68)$ & $16(66.7)$ \\
\hline & & 3 & $3(12)$ & $2(8.3)$ & $8(32)$ & $8(33.3)$ \\
\hline & & 4 & & $1(4.2)^{* *}$ & & \\
\hline \multirow{9}{*}{ Color match and translucency } & \multirow{2}{*}{ Baseline } & 1 & $31(96.9)$ & $32(100)$ & $31(96.9)$ & $31(96.9)$ \\
\hline & & 2 & $1(3.1)$ & & $1(3.1)$ & $1(3.1)$ \\
\hline & \multirow{2}{*}{6 months } & 1 & $31(96.9)$ & $32(100)$ & $31(96.9)$ & $30(93.8)$ \\
\hline & & 2 & $1(3.1)$ & & $1(3.1)$ & $2(6.3)$ \\
\hline & \multirow{2}{*}{18 months } & 1 & $30(100)$ & $31(100)$ & $29(96.7)$ & $28(93.3)$ \\
\hline & & 2 & & & $1(3.3)$ & $2(6.7)$ \\
\hline & \multirow{3}{*}{36 months } & 1 & $25(100)$ & $23(95.8)$ & $23(92)$ & $23(95.8)$ \\
\hline & & 2 & & & $1(4)$ & $1(4.2)$ \\
\hline & & 3 & & $1(4.2)$ & $1(4)$ & \\
\hline \multirow{8}{*}{ Anatomic form } & Baseline & 1 & $32(100)$ & $32(100)$ & $32(100)$ & $32(100)$ \\
\hline & \multirow{2}{*}{6 months } & 1 & $32(100)$ & $32(100)$ & $31(96.9)$ & $32(100)$ \\
\hline & & 4 & & & $1(3.1)$ & \\
\hline & \multirow{2}{*}{18 months } & 1 & $30(100)$ & $31(100)$ & $30(96.8)$ & $30(100)$ \\
\hline & & 4 & & & $1(3.2)$ & \\
\hline & \multirow{3}{*}{36 months } & 1 & $25(100)$ & $23(95.8)$ & $24(92.3)$ & $24(100)$ \\
\hline & & 3 & & & $1(3.8)$ & \\
\hline & & 4 & & $1(4.2)^{* *}$ & $1(3.8)^{* *}$ & \\
\hline
\end{tabular}

* Significant changes in surface and marginal staining in Groups 3 (baseline/36 months $p=0.01,6$ months/36 months $p=0.02$ ) and 4 (baseline/36 months $p=0.003,6$ months $/ 36$ months $p=0.03)$. ${ }^{* *}$ Due to partial restoration fracture.

The overall failure rates at 36 months were 3.8\%, $4.2 \%$, $7.4 \%$, and $7.7 \%$ for Groups 1-4, respectively. The failures were due to partial restoration loss in 5 teeth (1 tooth in Groups 1 , 2 , and 3 and 2 teeth in Group 4) and total restoration loss in 1 tooth (Group 3, Table 3).

At the end of the study, all restorations had clinically excellent surface gloss. The rate of restorations with excellent color match and anatomic form varied from $92 \%$ to $100 \%$. In the radiographic evaluation, many of the restorations were assigned a score of 2 at all recall appointments (Tables 2 and $3)$.

At 36 months, secondary caries was detected in 3 teeth (1 tooth in Group 2, 2 teeth in Group 3). In Group 4, secondary caries was detected in one patient at 18 months but the patient did not attend to further recall (Table 4).

In regard to proximal contact point criteria, many of the restorations were given a score of 4 , because of physiological spaces in primary dentition (Table 3). Those restorations were not repaired and no clinical symptoms were detected during the evaluation period. Postoperative sensitivity, tooth fracture, localized soft tissue reactions, and oral and somatic psychiatric symptoms were not detected throughout the study (Table 4).

With respect to intragroup differences over time, statistically significant differences were found for the surface and marginal staining and for the marginal adaptation criteria $(p<0.05)$. Surface and marginal staining for the restorations in Groups 3 and 4 had increased significantly at 36 months compared to those recorded at baseline and at 6 months ( $p<$ $0.05)$. Marginal adaptation of restorations in Groups 1 and 2 had decreased significantly at 36 months compared to those at baseline and at 6 months $(p<0.05)$. Marginal adaptation of restorations in Group 3 had decreased significantly at 18 months and 36 months compared to those at baseline and 
TABLE 3: Functional properties of the groups.

\begin{tabular}{|c|c|c|c|c|c|c|}
\hline Criteria & Time & Score & $\begin{array}{c}\text { Group } 1 \\
n(\%)\end{array}$ & $\begin{array}{c}\text { Group } 2 \\
n(\%)\end{array}$ & $\begin{array}{c}\text { Group } 3 \\
n(\%)\end{array}$ & $\begin{array}{c}\text { Group } 4 \\
n(\%)\end{array}$ \\
\hline \multirow{11}{*}{ Fracture of restorative material } & Baseline & 1 & $32(100)$ & $32(100)$ & $32(100)$ & $32(100)$ \\
\hline & \multirow{3}{*}{6 months } & 1 & $30(93.8)$ & $32(100)$ & $31(96.9)$ & $31(96.9)$ \\
\hline & & 3 & $1(3.1)$ & & & \\
\hline & & 4 & $1(3.1)$ & & $1(3.1)$ & $1(3.1)$ \\
\hline & \multirow{3}{*}{18 months } & 1 & $29(93.5)$ & $30(96.8)$ & $30(96.8)$ & $29(93.5)$ \\
\hline & & 3 & $1(3.2)$ & $1(3.2)$ & & \\
\hline & & 4 & $1(3.2)$ & & $1(3.2)$ & $2(6.5)$ \\
\hline & \multirow{4}{*}{36 months } & 1 & $24(92.3)$ & $23(95.8)$ & $24(88.9)$ & $24(92.3)$ \\
\hline & & 3 & $1(3.8)$ & & $1(3.7)$ & \\
\hline & & 4 & $1(3.8)$ & $1(4.2)$ & $1(3.7)$ & $2(7.7)$ \\
\hline & & 5 & & & $1(3.7)$ & \\
\hline \multirow{13}{*}{ Marginal adaptation* } & \multirow{2}{*}{ Baseline } & 1 & $32(100)$ & $32(100)$ & $31(96.9)$ & $31(96.9)$ \\
\hline & & 3 & & & $1(3.1)$ & $1(3.1)$ \\
\hline & \multirow{4}{*}{6 months $^{* *}$} & 1 & $28(87.5)$ & $27(84.4)$ & $13(40.6)$ & $20(62.5)$ \\
\hline & & 2 & $2(6.3)$ & $2(6.3)$ & $9(28.1)$ & $3(9.4)$ \\
\hline & & 3 & $2(6.3)$ & $3(9.4)$ & $9(28.1)$ & $8(25)$ \\
\hline & & 4 & & & $1(3.1)$ & $1(3.1)$ \\
\hline & \multirow{4}{*}{18 months $^{* * *}$} & 1 & $20(66.7)$ & $20(64.5)$ & $4(12.9)$ & $10(32.3)$ \\
\hline & & 2 & & & & $1(3.2)$ \\
\hline & & 3 & $10(33.3)$ & $11(35.5)$ & $26(83.9)$ & $18(58.1)$ \\
\hline & & 4 & & & $1(3.2)$ & $2(6.5)$ \\
\hline & \multirow{3}{*}{36 months $^{* * * *}$} & 1 & $12(48)$ & $11(45.8)$ & $2(7.7)$ & $2(7.7)$ \\
\hline & & 3 & $13(52)$ & $12(50)$ & $23(88.5)$ & $22(84.6)$ \\
\hline & & 4 & & $1(4.2)^{* * * * *}$ & $1(3.8)^{* * * * *}$ & $2(7.7)^{* * * * *}$ \\
\hline \multirow{11}{*}{ Proximal contact point } & \multirow{2}{*}{ Baseline } & 3 & $15(46.9)$ & $14(43.8)$ & $16(50)$ & $13(40.6)$ \\
\hline & & 4 & $17(53.1)$ & $18(56.3)$ & $16(50)$ & $19(59.4)$ \\
\hline & \multirow{2}{*}{6 months } & 3 & $15(46.9)$ & $20(62.5)$ & $19(59.4)$ & $13(40.6)$ \\
\hline & & 4 & $17(53.1)$ & $12(37.5)$ & $13(40.6)$ & $19(59.4)$ \\
\hline & \multirow{3}{*}{18 months } & 2 & $1(3.3)$ & & & $1(3.3)$ \\
\hline & & 3 & $15(50)$ & $18(58.1)$ & $20(66.7)$ & $14(46.7)$ \\
\hline & & 4 & $14(46.7)$ & 13 (41.9) & $10(33.3)$ & $15(50)$ \\
\hline & \multirow{4}{*}{36 months } & 0 & $1(4)$ & $1(4.2)$ & $3(12)$ & \\
\hline & & 2 & $1(4)$ & & & $1(4.2)$ \\
\hline & & 3 & $10(40)$ & $8(33.3)$ & $12(48)$ & $9(37.5)$ \\
\hline & & 4 & $13(52)$ & $15(62.5)$ & $10(40)$ & $14(58.3)$ \\
\hline \multirow{10}{*}{ Radiographic examination } & \multirow{3}{*}{ Baseline } & 2 & $31(96.9)$ & $31(96.9)$ & $30(93.8)$ & $31(96.9)$ \\
\hline & & 3 & & $1(3.1)$ & $1(3.1)$ & \\
\hline & & 4 & $1(3.1)$ & & $1(3.1)$ & $1(3.1)$ \\
\hline & \multirow{3}{*}{18 months } & 2 & $29(96.7)$ & $30(96.8)$ & $29(96.7)$ & $29(96.7)$ \\
\hline & & 3 & & $1(3.2)$ & & \\
\hline & & 4 & $1(3.3)$ & & $1(3.3)$ & $1(3.3)$ \\
\hline & \multirow{4}{*}{36 months } & 0 & & $1(4.3)$ & & $1(4.3)$ \\
\hline & & 2 & $23(95.8)$ & $21(91.3)$ & $22(91.7)$ & $21(91.3)$ \\
\hline & & 3 & & $1(4.3)$ & $1(4.2)$ & \\
\hline & & 4 & $1(4.2)$ & & $1(4.2)$ & $1(4.3)$ \\
\hline
\end{tabular}

${ }^{*}$ Significant changes in marginal adaptation in Group 1 (baseline $/ 36$ months $p=0.000,6$ months $/ 36$ months $p=0.003$ ); Group 2 (baseline $/ 36$ months $p=0.000,6$ months $/ 36$ months $p=0.001$ ); Group 3 (baseline $/ 18$ months $p=0.000$, baseline $/ 36$ months $p=0.000,6$ months $/ 18$ months $p=0.022$, and 6 months $/ 36$ months $p=0.000$ ); Group 4 (baseline/18 months $p=0.000$, baseline $/ 36$ months $p=0.000$, and 6 months $/ 36$ months $p=0.000$ ). ${ }^{* *}$ Significant differences between Groups 1 and $3(p=0.008)$ and 2 and $3(p=0.017)$ at 6 months, ${ }^{* * *}$ Groups 1 and $3(p=0.001)$ and 2 and $3(p=0.002)$ at 18 months, and ${ }^{* * * *}$ Groups 1 and $4(p=0.032)$ at 36 months. ${ }^{* * * *}$ Due to partial restoration fracture. 
TABLE 4: Biological properties of the groups.

\begin{tabular}{|c|c|c|c|c|c|c|}
\hline Criteria & Time & Score & $\begin{array}{c}\text { Group } 1 \\
n(\%)\end{array}$ & $\begin{array}{c}\text { Group } 2 \\
n(\%)\end{array}$ & $\begin{array}{c}\text { Group } 3 \\
n(\%)\end{array}$ & $\begin{array}{c}\text { Group } 4 \\
n(\%)\end{array}$ \\
\hline \multirow{4}{*}{$\begin{array}{l}\text { Postoperative sensitivity } \\
\text { and tooth vitality }\end{array}$} & Baseline & 1 & $32(100)$ & $32(100)$ & $32(100)$ & $32(100)$ \\
\hline & 6 months & 1 & $32(100)$ & $32(100)$ & $32(100)$ & $32(100)$ \\
\hline & 18 months & 1 & $30(100)$ & $31(100)$ & $30(100)$ & $30(100)$ \\
\hline & 36 months & 1 & $25(100)$ & $24(100)$ & $25(100)$ & $24(100)$ \\
\hline \multirow{9}{*}{ Secondary caries } & Baseline & 1 & $32(100)$ & $32(100)$ & $32(100)$ & $32(100)$ \\
\hline & \multirow{2}{*}{6 months } & 1 & $31(96.9)$ & $32(100)$ & $32(100)$ & $32(100)$ \\
\hline & & 3 & $1(3.1)$ & & & \\
\hline & \multirow{3}{*}{18 months } & 1 & $30(100)$ & $30(96.8)$ & $29(96.7)$ & $29(96.7)$ \\
\hline & & 2 & & & $1(3.3)$ & \\
\hline & & 3 & & $1(3.2)$ & & $1(3.3)$ \\
\hline & \multirow{3}{*}{36 months } & 1 & $25(100)$ & $23(95.8)$ & $23(92)$ & $24(100)$ \\
\hline & & 2 & & & $1(4)$ & \\
\hline & & 3 & & $1(4.2)$ & $1(4)$ & \\
\hline \multirow{4}{*}{ Tooth cracks and fractures } & Baseline & 1 & $32(100)$ & $32(100)$ & $32(100)$ & $32(100)$ \\
\hline & 6 months & 1 & $32(100)$ & $32(100)$ & $32(100)$ & $32(100)$ \\
\hline & 18 months & 1 & $30(100)$ & $31(100)$ & $30(100)$ & $30(100)$ \\
\hline & 36 months & 1 & $25(100)$ & $24(100)$ & $25(100)$ & $24(100)$ \\
\hline \multirow{4}{*}{$\begin{array}{l}\text { Localized reactions of soft } \\
\text { tissue in direct contact with } \\
\text { the restoration }\end{array}$} & Baseline & 1 & $32(100)$ & $32(100)$ & $32(100)$ & $32(100)$ \\
\hline & 6 months & 1 & $32(100)$ & $32(100)$ & $32(100)$ & $32(100)$ \\
\hline & 18 months & 1 & $30(100)$ & $31(100)$ & $30(100)$ & $30(100)$ \\
\hline & 36 months & 1 & $25(100)$ & $24(100)$ & $25(100)$ & $24(100)$ \\
\hline \multirow{4}{*}{$\begin{array}{l}\text { Oral and } \\
\text { somatic/psychiatric } \\
\text { symptoms }\end{array}$} & Baseline & 1 & $32(100)$ & $32(100)$ & $32(100)$ & $32(100)$ \\
\hline & 6 months & 1 & $32(100)$ & $32(100)$ & $32(100)$ & $32(100)$ \\
\hline & 18 months & 1 & $30(100)$ & $31(100)$ & $30(100)$ & $30(100)$ \\
\hline & 36 months & 1 & $25(100)$ & $24(100)$ & 25 (100) & $24(100)$ \\
\hline
\end{tabular}

at 6 months. Finally, marginal adaptation of restorations in Group 4 had decreased significantly at 18 months and 36 months compared to at baseline and at 36 months compared to 6 months $(p<0.05)$ (Tables 2 and 3 ).

Regarding intergroup differences, statistically significant differences were found for the marginal adaptation criterion $(p<0.05)$. At 6 months and at 18 months, there was a statistically significant difference between Group 1 and Group 3 and between Group 2 and Group 3. At 36 months, there was a statistically significant difference between Group 1 and Group $4(p<0.05)$ (Table 3).

\section{Discussion}

Split-mouth studies offer a way of comparing restorations intraindividually and offer the advantage of limiting patientdependent variables [15]. The major disadvantage of splitmouth studies, however, is the difficulty in gathering patients with a sufficient number of similar types of caries lesions. The sample size of the present study (32 patients) may be regarded as small, but it reflects the great difficulty in finding four similar proximal caries lesions in primary teeth of one individual. The lack of split-mouth studies including four
Class II restorations in primary teeth in the literature also is an indication of this difficulty.

Available studies on the clinical performance of restorative materials in primary teeth mainly focus on the efficacy of compomer, amalgam, and glass ionomer cement. A few studies have reported on the clinical success of resin composites in primary teeth $[12,15-20]$. In the majority of these studies, the restorations were assessed according to the Ryge criteria. Only one retrospective and one prospective study used the FDI criteria, and these focused on survival of the restorations rather than giving a detailed analysis as was done in the present study $[12,21]$.

Hickel et al. [14] have proposed a system according to which the results of studies that used the Ryge criteria can be compared to those that used the FDI criteria. According to this system, the FDI scores of 1 and 2 correspond to a Ryge score of alpha, a FDI score of 3 corresponds to a Ryge score of bravo, and the FDI scores of 4 and 5 correspond to the Ryge scores of charlie and delta. Application of this conversion system to the present results gives the following ranges of alpha and bravo scores for the surface and marginal staining criterion of the four groups: $66.7-88 \%$ (alpha) and $8.3-$ $33.3 \%$ (bravo). These results are in accordance with previously reported ranges of marginal discoloration of $66.7-81 \%$ for 
alpha and $14-31.6 \%$ for bravo according to the Ryge criteria $[17,18,20]$.

As for marginal adaptation, the rates reported in literature are $36.8-92 \%$ for alpha and 5-63.2\% for bravo scores, indicating a wide variation between the different studies $[15,17,18,20]$. Compared to those of the aforementioned studies, the rate of alpha scores in the present study is lower (7.7-48\%) whereas the rate of bravo is higher (50-88.5\%), a finding that may be related to the longer evaluation time of the restorations in the present study. No previous study in primary teeth has used an evaluation time of 3 years, and it is reasonable to expect a decrease in the alpha grading after 3 years compared to that after 18 months or 2 years as reported in the aforementioned studies [15, 17, 19, 20, 22, 23].

The manufacturers of the two etch-and-rinse adhesive systems recommend etching of the enamel and dentin for 15 seconds regardless of whether the procedure is used in primary or permanent teeth. In the present study, an etching time of 30 seconds was used for enamel [24]. Although no consensus has been reached regarding the most appropriate etching time for primary enamel, it is generally accepted that a longer etching time is required owing to the presence of an outer prismless layer [25]. The dentin may be etched as well during the enamel etching process, frequently at the bottom of the proximal box in primary teeth where no enamel layer is left. This could lead to an overetching of the dentin and reduced bond strength of the restorations. However, the results of the present study demonstrated no such effect on the clinical retention of the restorations.

The morphological differences between primary enamel and dentin require different mechanisms of action. The $\mathrm{pH}$ of the self-etch adhesive systems should be sufficiently low to remove the smear layer but should also be sufficiently high so as not to cause excessive demineralization of the dentin substrate $[5,26]$. It has been suggested that self-etch adhesive systems might be more suitable for primary teeth owing to their less aggressive etching of the less mineralized primary dentin $[27,28]$. The $\mathrm{pH}$ of the two-step and one-step selfetch adhesives used in the current study was 1.7 and 2.3, respectively $[29,30]$, thus classifying them as mild adhesive systems [29]. In the present study, the two etch-and-rinse adhesive systems resulted in better marginal adaptation and less marginal staining of the restorations than the two selfetch adhesive systems. This result may be attributed to the higher $\mathrm{pH}$ of the self-etch adhesive systems resulting in a shallow etching pattern in primary enamel and influencing the marginal integrity of the restorations $[4,31,32]$. In order to increase marginal integrity, preetching of the enamel has been suggested [33, 34]. However, contamination of the dentin with phosphoric acid is inevitable causing decalcification that is too deep to be completely infiltrated by the adhesive $[35,36]$. The morphological differences between primary and permanent dentin mean that decalcification would be more pronounced on primary dentin [37]. In the present study, no preetching of the enamel was done. This decision was made for the aforementioned reasons as well as the aim to ascertain the absolute effect of the self-etch adhesive system on primary teeth. The fact that we found better surface and marginal adaptation and less marginal staining of the restorations treated with etch-and-rinse adhesive systems than self-etch adhesive systems may indicate the need for preetching primary enamel and for clinical studies in primary teeth looking into this aspect.

Numerous in vitro studies on primary teeth have found less marginal leakage and greater bond strengths with the etch-and-rinse adhesive systems as compared to self-etch adhesive systems $[4,38,39]$. Of the etch-and-rinse adhesive systems used in the present study, Ramires-Romito et al. [39] reported higher microtensile bond strength of primary enamel with OptiBond FL than with the self-etch version, OptiBond Solo SE. Lemos et al. [40] demonstrated higher bond strength and a better-defined etching pattern and resin tags on primary enamel with OptiBond FL than with OptiBond All-in-One. Despite the results reported for primary enamel, it has been suggested that optimal bonding to primary dentin is achieved with self-etch adhesive systems [4]. Nevertheless, there have been limited studies so far and the results regarding the survival of restorations made with etch-and-rinse versus self-etch adhesive systems in primary teeth are conflicting $[12,15]$.

There has been no other clinical study that tested the four current adhesive systems in primary teeth whereas studies with these adhesive systems in permanent teeth have been reported [41, 42]. Delbons et al. [41] reported no statistically significant differences among the four adhesive systems with respect to all parameters including retention, marginal adaptation, and staining. In a recent systemic review and a meta-analysis, it was concluded that besides adhesive strategy (i.e., etch-and-rinse versus self-etch), the specific brand is also important as there is a wide variation in the performance of adhesive systems $[43,44]$. The present study, however, did find differences between etch-and-rinse adhesive systems and self-etch adhesive systems. Similar to our results, Perdigão et al. [42] reported more enamel marginal deficiencies for the self-etch adhesive systems and similar retention rates for etch-and rinse and self-etch adhesive systems.

Not only the adhesive systems but many other factors determine the durability of restorations in primary teeth. The failure rates for composite restorations vary between $13.6 \%$ and $22.5 \%$ in primary teeth $[12,15,17,21,23]$. The lower failure rates found in the present study may be related to the use of rubber dam, which has been found to be an important factor in achieving a higher survival rate of composite restorations [12]. It is also worth mentioning that all restored teeth had occlusal and proximal contacts, which could have been important for the survival of the restorations [14].

In the current study, many of the restorations were assigned a score of 4 for the proximal contact point criteria, implying the need for repair. According to the clinical experience of the present authors, many intact primary teeth are also given a score of 4 because of the physiological spaces in primary dentition. It was decided, therefore, not to repair those restorations, and no clinical symptoms were detected in the present study.

In addition to the aforementioned criteria, two modifications were made for the radiographic evaluation parameter. In the parameter, the steps and gaps between the tooth and 
restoration were classified from 1 to 5 according to their dimensions. In the FDI criteria, although positive/negative steps $<150 \mu \mathrm{m}$ were scored as 2 , gap dimensions $<150 \mu \mathrm{m}$ were not included. It was learned that the reason of it was due to inadequate resolution of the radiographs that may prevent proper radiographic analysis (correspondence with Dr. R. Hickel). In the present study, the score 2 included gaps $<150 \mu \mathrm{m}$ as the resolution of the radiographs was adequate for analysis. Three restorations were detected with a gap size $>250 \mu \mathrm{m}$, implying the need for repair according to the radiographic evaluation parameter of the FDI criteria. Those restorations were not repaired or replaced because there has been no report about the gap dimensions causing clinical problems in primary teeth. No clinical symptoms were detected during the clinical follow-up period in the current research.

In the current research, the clinical performance of composite restorations was evaluated using the FDI criteria. The null hypothesis was rejected, as better marginal adaptation and less surface and marginal staining were found in restorations placed using etch-and-rinse adhesive systems than self-etch adhesive systems.

\section{Conclusions}

Under the limitations of this study, the following conclusions can be drawn:

(1) In the current study, better marginal adaptation was found in composite restorations made with etch-andrinse adhesive systems than with self-etch adhesives.

(2) Marginal staining tended to increase over time in restorations made with self-etch adhesives.

\section{Competing Interests}

The authors declare that there is no conflict of interests regarding the publication of this paper.

\section{Acknowledgments}

The authors would like to express their deepest gratitude to Professor Dr. Anne Peutzfeldt for revision of the manuscript.

\section{References}

[1] V. Yengopal, S. Y. Harneker, N. Patel, and N. Siegfried, "Dental fillings for the treatment of caries in the primary dentition," Cochrane Database of Systematic Reviews, vol. 15, no. 2, Article ID CD004483, 2009.

[2] V. Buerkle, J. Kuehnisch, M. Guelmann, and R. Hickel, "Restoration materials for primary molars-results from a European survey," Journal of Dentistry, vol. 33, no. 4, pp. 275-281, 2005.

[3] R. Franzon, L. F. Guimarães, C. E. Magalhães, A. N. Haas, and F. B. Araujo, "Outcomes of one-step incomplete and complete excavation in primary teeth: a 24-month randomized controlled trial," Caries Research, vol. 48, no. 5, pp. 376-383, 2014.

[4] T. K. Swanson, R. J. Feigal, D. Tantbirojn, and J. S. Hodges, "Effect of adhesive systems and bevel on enamel margin integrity in primary and permanent teeth," Pediatric Dentistry, vol. 30, no. 2, pp. 134-140, 2008.

[5] S. Uekusa, K. Yamaguchi, M. Miyazaki, K. Tsubota, H. Kurokawa, and Y. Hosoya, "Bonding efficacy of single-step selfetch systems to sound primary and permanent tooth dentin," Operative Dentistry, vol. 31, no. 5, pp. 569-576, 2006.

[6] C. Yeşilyurt and B. Bulucu, "Bond strength of total-etch and self-etch dentin adhesive systems on peripheral and central dentinal tissue: a microtensile bond strength test," The Journal of Contemporary Dental Practice, vol. 7, no. 2, pp. 26-36, 2006.

[7] K. Nozaka, Y. Suruga, and E. Amari, "Microleakage of composite resins in cavities of upper primary molars," International Journal of Paediatric Dentistry, vol. 9, no. 3, pp. 185-194, 1999.

[8] D. A. Sumikawa, G. W. Marshall, L. Gee, and S. J. Marshall, "Microstructure of primary tooth dentin," Pediatric Dentistry, vol. 21, no. 7, pp. 439-444, 1999.

[9] J. E. Nör, R. J. Feigal, J. B. Dennison, and C. A. Edwards, "Dentin bonding: SEM comparison of the dentin surface in primary and permanent teeth," Pediatric Dentistry, vol. 19, no. 4, pp. 246-252, 1997.

[10] S. Mithiborwala, V. Chaugule, A. K. Munshi, and V. Patil, "A comparison of the resin tag penetration of the total etch and the self-etch dentin bonding systems in the primary teeth: an in vitro study," Contemporary Clinical Dentistry, vol. 3, no. 2, pp. 158-163, 2012.

[11] L. Casagrande, D. M. Dalpian, T. M. Ardenghi et al., "Randomized clinical trial of adhesive restorations in primary molars. 18Month results," American Journal of Dentistry, vol. 26, no. 6, pp. 351-355, 2013.

[12] K. Bücher, I. Metz, V. Pitchika, R. Hickel, and J. Kühnisch, "Survival characteristics of composite restorations in primary teeth," Clinical Oral Investigations, vol. 19, no. 7, pp. 1653-1662, 2014.

[13] U. Mohan Das, D. Viswanath, U. Azher, and N. Marwah, "Clinical evaluation of resin composite and resin modified glass ionomer in class III restorations of primary maxillary incisors: a comparative in vivo study," International Journal of Clinical Pediatric Dentistry, vol. 2, pp. 13-19, 2009.

[14] R. Hickel, J.-F. Roulet, S. Bayne et al., "Recommendations for conducting controlled clinical studies of dental restorative materials," Clinical Oral Investigations, vol. 11, no. 1, pp. 5-33, 2007.

[15] I. Andersson-Wenckert and K. Sunnegårdh-Grönberg, "Flowable resin composite as a class II restorative in primary molars: a two-year clinical evaluation," Acta Odontologica Scandinavica, vol. 64, no. 6, pp. 334-340, 2006.

[16] A. B. Fuks, F. B. Araujo, L. B. Osorio, P. E. Hadani, and A. S. Pinto, "Clinical and radiographic assessment of Class II esthetic restorations in primary molars," Pediatric Dentistry, vol. 22, no. 6, pp. 479-485, 2000.

[17] N. K. Ersin, U. Candan, A. Aykut, Ö. Onçag, C. Eronat, and T. Kose, "A clinical evaluation of resin-based composite and glass ionomer cement restorations placed in primary teeth using the ART approach: results at 24 months," Journal of the American Dental Association, vol. 137, no. 11, pp. 1529-1536, 2006.

[18] C. A. Oliveira, P. F. Dias, M. P. Dos Santos, and L. C. Maia, "Split mouth randomized controlled clinical trial of beveled cavity preparations in primary molars: an 18-Month follow up," Journal of Dentistry, vol. 36, no. 9, pp. 754-758, 2008.

[19] F. M. Pascon, K. R. Kantovitz, A. S. Caldo-Teixeira et al., "Clinical evaluation of composite and compomer restorations 
in primary teeth: 24-month results," Journal of Dentistry, vol. 34, no. 6, pp. 381-388, 2006.

[20] M. W. Roberts, C. L. Broring, and J. P. Moffa, "Two-year clinical evaluation of a proprietary composite resin for the restoration of primary posterior teeth," Pediatric Dentistry, vol. 7, no. 1, pp. 14-18, 1985.

[21] F. Sengul and T. Gurbuz, "Clinical evaluation of restorative materials in primary teeth class II lesions," The Journal of Clinical Pediatric Dentistry, vol. 39, no. 4, pp. 315-321, 2015.

[22] A. B. Fuks, "Pulp therapy for the primary and young permanent dentitions," Dental Clinics of North America, vol. 44, no. 3, pp. 571-596, 2000.

[23] M. P. A. Dos Santos, R. R. Luiz, and L. C. Maia, "Randomised trial of resin-based restorations in Class I and Class II beveled preparations in primary molars: 48-month results," Journal of Dentistry, vol. 38, no. 6, pp. 451-459, 2010.

[24] Y. Hosoya, "The effect of acid etching times on ground primary enamel," The Journal of Clinical Pediatric Dentistry, vol. 15, no. 3, pp. 188-194, 1991.

[25] O. Pittayawutwinit, "The applications of acid etching in pediatric dentistry: a review," Kerala Dental Journal, vol. 3, no. 1, pp. $9-15,2000$.

[26] H. Sano, T. Takatsu, B. Ciucchi, J. A. Horner, W. G. Matthews, and D. H. Pashley, "Nanoleakage: leakage within the hybrid layer," Operative Dentistry, vol. 20, no. 1, pp. 18-25, 1995.

[27] R. Osorio, F. S. Aguilera, P. R. Otero et al., "Primary dentin etching time, bond strength and ultra-structure characterization of dentin surfaces," Journal of Dentistry, vol. 38, no. 3, pp. 222-231, 2010.

[28] C. Kaaden, G. Schmalz, and J. M. Powers, "Morphological characterization of the resin-dentin interface in primary teeth," Clinical Oral Investigations, vol. 7, no. 4, pp. 235-240, 2003.

[29] G. Grégoire and A. Millas, "Microscopic evaluation of dentin interface obtained with 10 contemporary self-etching systems: correlation with their pH," Operative Dentistry, vol. 30 , no. 4 , pp. 481-491, 2005.

[30] Y. Nishitani, M. Yoshiyama, B. Wadgaonkar et al., "Activation of gelatinolytic/collagenolytic activity in dentin by self-etching adhesives," European Journal of Oral Sciences, vol. 114, no. 2, pp. 160-166, 2006.

[31] J. Perdigão, L. Lopes, P. Lambrechts, J. Leitão, B. Van Meerbeek, and G. Vanherle, "Effects of a self-etching primer on enamel shear bond strengths and SEM morphology," American Journal of Dentistry, vol. 10, no. 3, pp. 141-146, 1997.

[32] J. Perdigão and S. Geraldeli, "Bonding characteristics of selfetching adhesives to intact versus prepared enamel," Journal of Esthetic and Restorative Dentistry, vol. 15, no. 1, pp. 32-42, 2003.

[33] V. V. Gordan, M. A. Vargas, D. S. Cobb, and G. E. Denehy, "Evaluation of adhesive systems using acidic primers," American Journal of Dentistry, vol. 10, no. 5, pp. 219-223, 1997.

[34] T. L. Lenzi, C. De Almeida Brandão Guglielmi, C. B. Umakoshi, and D. P. Raggio, "One-step self-etch adhesive bonding to preetched primary and permanent enamel," Journal of Dentistry for Children, vol. 80, no. 2, pp. 57-61, 2013.

[35] Y. Torii, K. Itou, Y. Nishitani, K. Ishikawa, and K. Suzuki, "Effect of phosphoric acid etching prior to self-etching primer application on adhesion of resin composite to enamel and dentin," American Journal of Dentistry, vol. 15, no. 5, pp. 305308, 2002.

[36] K. L. Van Landuyt, P. Kanumilli, J. De Munck, M. Peumans, P. Lambrechts, and B. Van Meerbeek, "Bond strength of a mild self-etch adhesive with and without prior acid-etching," Journal of Dentistry, vol. 34, no. 1, pp. 77-85, 2006.

[37] V. Bolaños-Carmona, S. González-López, C. De Haro-Muñoz, and M. T. Briones-Luján, "Interfacial morphology and bond strength of self-etching adhesives to primary dentin with or without acid etching," Journal of Biomedical Materials Research Part B: Applied Biomaterials, vol. 87, no. 2, pp. 499-507, 2008.

[38] C. G. Cecilia, C. G. Ballesta, O. C. Lillo, and L. P. Lajarin, "Shear bond strength of a self-etching adhesive in primary and permanent dentition," American Journal of Dentistry, vol. 18, no. 5, pp. 331-334, 2005.

[39] A. C. D. Ramires-Romito, A. Reis, A. D. Loguercio et al., "Microtensile bond strength of sealant and adhesive systems applied to occlusal primary enamel," American Journal of Dentistry, vol. 20, no. 2, pp. 114-120, 2007.

[40] L. V. F. M. Lemos, K. R. Felizardo, S. I. Myaki, M. B. Lopes, and S. K. Moura, "Bond strength and morphology of resin materials applied to the occlusal surface of primary molars," International Journal of Paediatric Dentistry, vol. 22, no. 6, pp. 435-441, 2012.

[41] F. B. Delbons, J. Perdigão, E. Araujo et al., "Randomized clinical trial of four adhesion strategies in posterior restorations-18month results," Journal of Esthetic and Restorative Dentistry, vol. 27, no. 2, pp. 107-117, 2015.

[42] J. Perdigão, M. Dutra-Corrêa, C. H. C. Saraceni, M. T. Ciaramicoli, V. H. Kiyan, and C. S. Queiroz, "Randomized clinical trial of four adhesion strategies: 18-month results," Operative Dentistry, vol. 37, no. 1, pp. 3-11, 2012.

[43] S. D. Heintze, C. Ruffieux, and V. Rousson, "Clinical performance of cervical restorations-a meta-analysis," Dental Materials, vol. 26, no. 10, pp. 993-1000, 2010.

[44] M. Peumans, J. De Munck, A. Mine, and B. Van Meerbeek, "Clinical effectiveness of contemporary adhesives for the restoration of non-carious cervical lesions. A systematic review," Dental Materials, vol. 30, no. 10, pp. 1089-1103, 2014. 

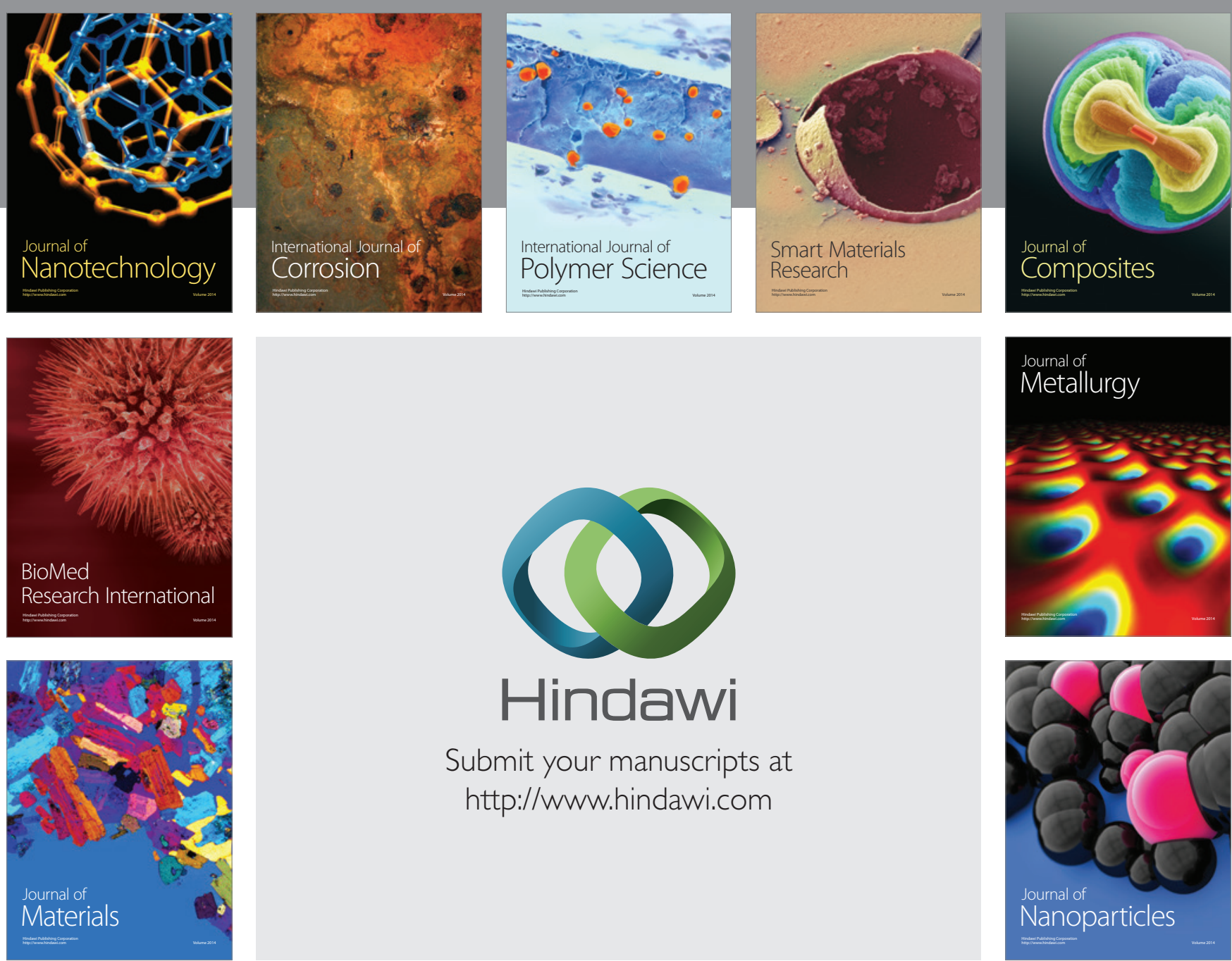

\section{Hindawi}

Submit your manuscripts at

http://www.hindawi.com

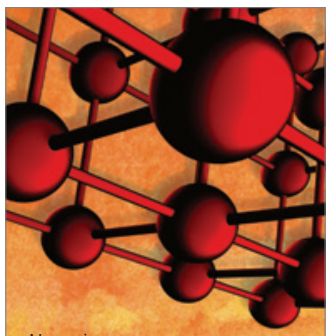

Materials Science and Engineering
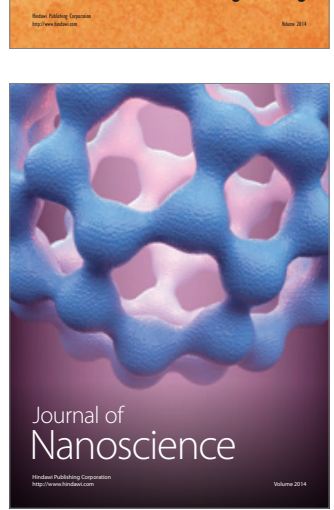
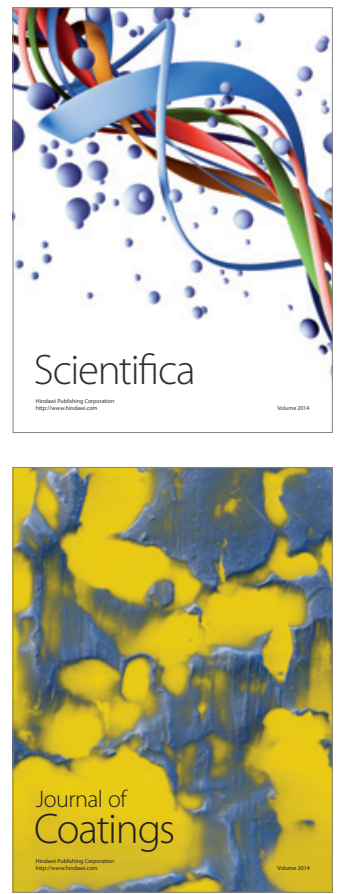
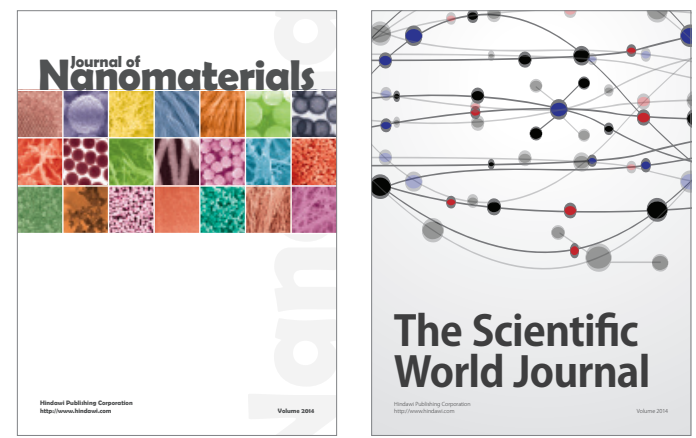

The Scientific World Journal
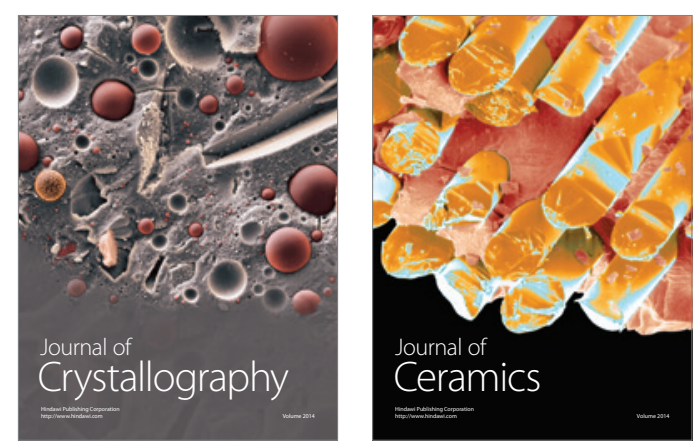
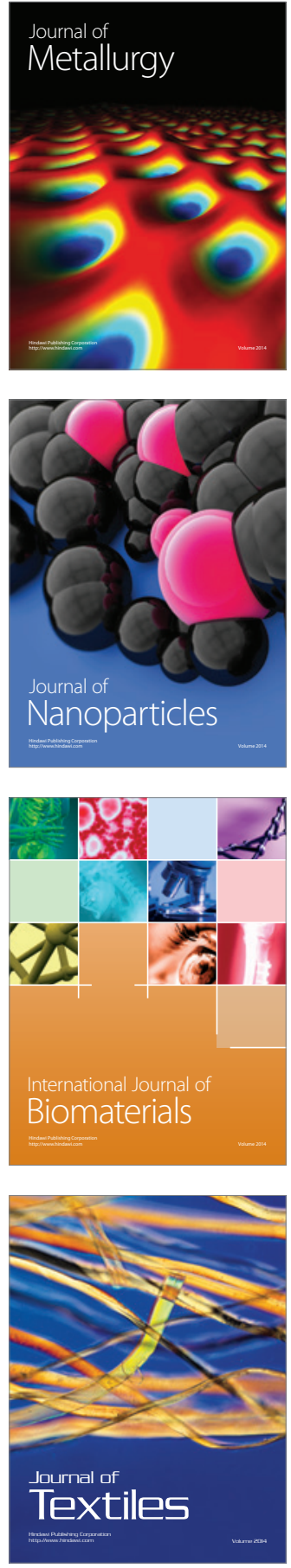